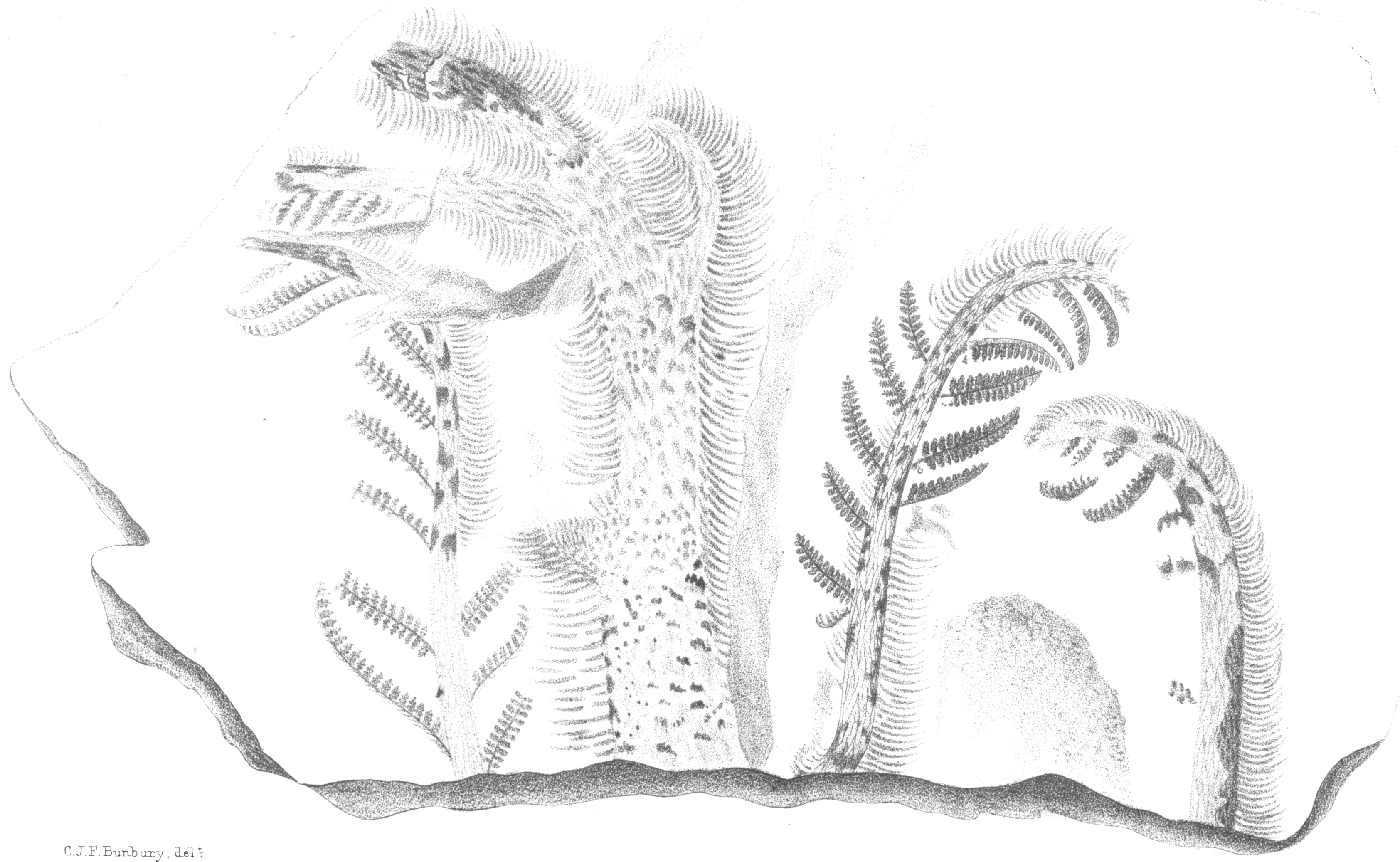

Fossil Fern from Cape Breton 
December 3, 1851.

T. A. Tagg, Esq., the Rev. H. M. De la Condamine, and W. B. Beaumont, Esq. were elected Fellows.

The following communications were read :-

1. Description of a peculiar Fossin Fern from the Sydney Coal Field, Cape Breton. By C. J. F. Bunbury, Esq., For. Sec. G.S.

\section{[PL. I.]}

Tre fossil plant of which I propose to give an account was communicated to me some time ago by Richard Brown, Esq., from the coalmines of Sydney, Cape Breton. I have shown it to several of my most learned friends, both botanists and geologists, who have all pronounced it to be entirely different from anything they had previously seen; nor have I been able to find any fossil with similar characters represented in any published work. The appearance of the specimen is indeed so peculiar and extraordinary, that its discoverer, who is well known to have an intimate acquaintance with the fossils of the Sydney coal-field, conceived it to present an actual union of the structures and characters of two distinct families. I have thought, therefore, that a careful description and figure of so singular a fossil might not be unacceptable to the Geological Society. Although I fear I must confess myself unable to give a very satisfactory explanation of the anomalies which it presents, still it seems desirable that the peculiarities of a specimen, at present unique, should be put upon record; and this notice, by exciting attention and discussion, may perhaps lead to a complete elucidation of the subject.

The slab of shale now before us exhibits four distinct portions of stem, which, from their relative position and proportion, may reasonably be supposed to have belonged to one plant. The largest, and that which appears to be the main stem, is about 4 inches long and half an inch broad, retaining pretty nearly this breadth for about half its length, and then tapering very gradually to the upper end. In direction it is wavy, curving first slightly to one side, and then more decidedly to the other, with so gentle and easy a curve as seems to show that this flexure was natural, and not the effect of pressure or violence. It shows no tendency to a dichotomous division, but bears three small and short lateral branches, which seem to be incompletely developed. The situation of these branches is irregularly alternate. The other stems which appear in the specimen are much more slender, and although their connexion with the main stem is lost, may be conjectured to be branches which sprung from it lower down. They likewise are curved, with an easy and evidently natural flexure, and two of them exhibit very plainly the circinate or involute curvature characteristic of Ferns. The surface of the main stem is pitted all over rather slightly and irregularly; the pits seeming to indicate the insertions of scales or hairs, or some such appendages ; there are no definite areola nor leaf-scars. In the smaller stems, or branches, on the other hand, the surface presents an appearance 
not unlike that of the young branches of Lepidodendron elegans, being marked with wavy and often intersecting striæ which form imperfect areoles ; but, on closer examination, we find that these areoles are not symmetrical or well-defined, nor do they bear any distinct scars of insertion.

I now proceed to describe what is most remarkable in this fossil,the leaves or appendages which it bears. On all the stems, and particularly on the largest, we observe great abundance of what appear to be acicular leaves, certainly much resembling those of some species of Lepidodendron. These are very closely crowded, very narrow, sharp-pointed, and with few exceptions, strongly incurved; for the most part indeed they are at first inclined downward, or towards the base of the stem, and then strongly curved in the opposite direction. Some of them show rather indistinct appearances of a central rib or ridge. The largest stem is thickly clothed throughout its length, and its lateral branches most densely, with these apparent leaves; they are now seen, indeed, only on the right and left sides, or margins of the stem, as it lies imbedded in the stone, but I conceive that they did exist likewise on the side which is now laid bare, and which is marked with the pits already mentioned. One of the smaller stems is clothed with them along the whole length of one side; on the remaining two they appear partially, occupying only certain portions, and being scarcely discoverable on others. But, besides these acicular leaves, which much resemble those of a Lycopodium, the smaller stems bear what are indisputably the leaves or fronds of a small Fern, apparently in an early and imperfectly developed state. These spring alternately from the two sides of the stem, but not uniformly, for they are wanting where the stems are most thickly clothed with the acicular leaves; some of these latter, however, are visible between the insertions of the fronds. The largest frond is about an inch long. They are of an oblong outline, narrow in proportion to their length, and much resemble the pinnæ of some of the more delicate species of Pecopteris, of the section Unita, such as $P$.plumosa and $P$. dentata. The back of the rhachis, where it is exposed to view, appears to be clothed with minute, narrow, pointed scales or appendages, resembling in miniature the supposed " acicular leaves" on the stem.

Such are the appearances presented by this singular fossil. That both the kinds of leaves, or leaf-like appendages, which I have described, really belong to the stems, and that the appearances are not due to any casual juxtaposition, will, I think, be quite evident to every one who examines the specimen. Mr. Richard Brown, the discoverer of the fossil, supposed it to be a peculiar species of Lepidodendron, bearing two different kinds of foliage,-namely, the leaves proper to that genus, and the fronds of a true Fern; and thus in fact combining in one plant the characters of the two families. Now, it is certainly true that the two orders* of Club-mosses and Ferns,

* I assume what I think has been sufficiently proved by M. Brongniart, that the Lepidodendra belonged to the family of Lycopodiacee, or were at any rate most closely related to them. 
although in general widely different in their outward appearance, are very closely allied in all essential points of structure, so that all botanists have agreed in placing them next to one another, and some of the most eminent have even united them under one head. Sir W. Hooker, for instance, in two or three of his admirable works on Ferns, has actually comprehended the Club-mosses as a subordinate group. Hence it would not be utterly inconceivable, that, in a former state of the world, there should have existed plants combining some of the peculiarities of the two orders, and uniting them more closely than is done by any existing form. I am inclined to think, however, that this hypothesis is not applicable to the specimen now before us.

On a close examination of the stem, we shall fail, I think, to discover the proper characters of a Lepidodendron. There is no appearance of that regular dichotomous division which has been justly insisted on by $\mathbf{M}$. Brongniart as an important characteristic of Lepidodendron; on the contrary, the only stem in this specimen which is branched, has branches irregularly alternate, and very inferior in size to the main axis. Again, the stems here have a wavy and winding character, an appearance of softness and flexibility, which I have not seen in any genuine Lepidodendron. In L. elegans and L. gracile, the most branched kinds with which I am acquainted, even the youngest and slenderest branches are almost always straight, and have a certain rigidity of character which is wanting here. Again, although the younger parts of the stem, in the specimen before us, exhibit superficial markings a good deal like those of the young branches of a Lepidodendron, yet the areoles are irregular and ill. defined, and without distinct leaf-scars. On the main stem all appearance of regular and definite areoles has vanished, and the surface is merely indented or pitted, in a manner very similar to what we observe in undoubted fossil Fern-stalks (stipites). On the other hand, it is well known how definite and regular are the areolar markings of true Lepidodendra, even on stems of great size and age*.

For these reasons, I can hardly believe that any part of the specimen in question belongs to the genus Lepidolendron. I may mention, too, that when $I$ showed it to the greatest of modern botanists, he pronounced the plant to be truly a Fern, and nothing else.

The conjecture I have to offer-for I can call it no more than a conjecture-is that this curious fossil may possibly be a Fern with a creeping stem or rhizome, such as are so commonly seen in moist tropical climates, creeping like ivy over mossy rocks and old trunks of trees. Polypodium incanum, $\mathscr{P}$. percussum, $\boldsymbol{P}$. vaccinifolium, and $\boldsymbol{P}$. lycopodioides are well-known examples of this mode of growth, and are often to be seen in botanical collections. The creeping stem of such Ferns has often a striking resemblance at first sight to a Lycopodium, as indeed is indicated by the name of one of the plants above-mentioned. At the same time it is by no means regularly dichotomous, but has an irregular ramification, often very similar to

* $L$. selaginoides (of the "Foss. Flora") is an apparent exception, but I strongly suspect that it is not a true Lepidodendron.

VOL. VIII.-PART I. 
that of the fossil from Cape Breton. I have already noticed that the older parts of the stem, in this fossil, bear superficial markings similar to what are often seen on the fossil stalks or stipites of Ferns. And as these marks are admitted, in the one case, to be due to the removal of chaffy scales, or other such appendages of the epidermis, so I think we may suppose them to be of similar origin in the other case. I am not of opinion, however, that the stems in the specimen before us can be properly the stipites of Ferns ; for their ramification, and especially the insertion of the fronds, is too irregular. On the other hand, the position of these fronds and their insertion on the stems appear to me consistent with the supposition that the whole belonged to a creeping Fern.

It remains to explain what, on this hypothesis, could be the nature of those appendages which so much resemble the leaves of a Lepidodendron. The only explanation I can suggest is, that they may possibly have been scales (palea), of the same nature as those which are so commonly found to clothe the creeping stems of Ferns. I must own, that among the recent Ferns with a stem of this character, I do not know any with scales similar to these in form or texture. But in Lomaria Magellanica, a Fern indeed very unlike our fossil in other respects, the rhizome and base of the stipes are clothed with long, narrow, pointed scales, of a peculiarly rigid character, and bearing, as I think, no small resemblance to the apparent leaves of the fossil in question. What strengthens my suspicion that these leaf-like bodies may be mere scales, is the presence of apparently similar, though much more minute, appendages on the rhachis of one of the fronds.

The only figure I have met with that bears any resemblance to this fossil, is that of Selaginites Erdmanni, in the sixth part of Germar's fine work on the fossils of Wettin. The plant there figured, although much larger than ours, has a certain degree of resemblance to it in ramification, and in the marking of its surface (particularly fig. A. pl. 26). The Wettin fossil, however, does not present the biform aspect which is so extraordinary in ours. Notwithstanding the opinion of so eminent a naturalist as M. Germar, I cannot help feeling great doubts whether his Selaginites really belongs to Lycopodiacece. Its ramification appears to me too irregular, its general form too thick and clumsy for that order of plants, and the supposed leaves with which its surface is covered, appear (in the plate) more like scales than true leaves.

To return to our Cape Breton fossil. If my explanation of its structure be correct (of which I feel by no means confident), it will indeed be less wonderful than was at first supposed, but will yet be an uncommonly interesting specimen; for instances of the fronds of fossil Ferns still attached to the stem are exceedingly rare. In formations of a later age than the Coal-measures (the Grès bigarré and the Wealden), a very few specimens have been found of Ferns* with the fronds still in their natural position, springing in a tuft from a small knotty rhizome; but I am not aware that anything similar has

* See the works of Schimper and Mougeot, and of Dunker. 
been observed in the Coal-formation. The rarity, indeed, of recognizable stems of Ferns in this formation, when compared with the profusion of their leaves, is quite remarkable, and might incline one to suspect that these plants were not fossilized on the spot where they grew. It is rare to find, in the Ferns of the Coal-measures, even the stipes or leaf-stalk completely preserved down to its base: the only specimen of this kind that I have seen is a beautiful Sphenopteris (I believe $S$. elegans) from the Edinburgh coal-field, in the collection of Mr. Hugh Miller. On the other hand, the state of preservation of the fronds themselves seems to show that they cannot have been transported from any great distance, and I am well aware that there are strong geological objections to any hypothesis of drifting, especially when we consider the vast extent of some coalfields. It is possible that a diligent examination of the immense carboniferous deposits of the United States and New Brunswick may hereafter throw some light on various obscure questions, both in Geology and Palæo-botany.

2. On the Lower Palaozorc Rocks at the Base of the Carboniferous Chain between Ravenstonedale and Ribblesdale. By the Rev. A. Sedgwick, F.R.S., G.S. \&c.

A GLANCE of the eye over the geological map of England shows us, in the upper part of the valley of the Eden, a very remarkable reentering angle in the base-line of the Carboniferous Limestone. Taking our point of departure from the foot of Stainmoor, we trace the Pennine Chain (which at Cross Fell reaches the height of nearly 3000 feet) in a direction about N.E. by N.; and the Yorkshire prolongation of the same carboniferous chain in a direction about S.S.W.; while another carboniferous chain, branching off from the former near Kirkby Stephen, may be traced in a semicircular sweep round the northern flanks of the great Cumbrian cluster of mountains. The re-entering angle in the base-line of the Pennine chain is partly accounted for by the intersection of two enormous breaks or faultsthe Pennine fault and the Craven fault*; and the whole country, from Brough and Kirkby Stephen to the foot of Stainmoor, is filled with broken masses of the Pennine chain, which have been rent off by the two lines of fracture, and thrown down, in great confusion, into the lower parts of the valley.

The Craven fault has been described in considerable detail by Professor Phillips $\uparrow$ and myself $\ddagger$. The Pennine fault, ranging near the

* See Phillips's Illustr. Geol. Yorksh. Part 2. pl. 24. fig. 14, and Geological Map, pl. 25.

$\dagger$ Trans. Geol. Soc. 2nd Ser. vol. iii. pp. 5-15; and Geol. Yorkshire, pp. 107, $120,8 \mathrm{c}$.

$\ddagger$ Trans. Geol. Soc. 2nd Ser. vol. iv. p. 60 et seq., and 69 et seq. I gave this great break among the lower strata of the carboniferous chain the name of the 